\title{
Inventory of the building stock in the city of Serres (Greece) for seismic vulnerability assessment and loss estimation
}

\author{
G. Panagopoulos ${ }^{1}$, E. Kirtas ${ }^{1}$, K. Mimidis ${ }^{2}$, I. Sous ${ }^{1}$, A. Kappos ${ }^{3}$, \\ I. Lialiampis ${ }^{1} \&$ D. Chasapis ${ }^{4}$ \\ ${ }^{I}$ Department of Civil Engineering and Surveying Engineering \\ and Geoinformatics, T.E.I. of Central Macedonia, Greece \\ ${ }^{2}$ Department of Civil Engineering, \\ Democritus University of Thrace, Greece \\ ${ }^{3}$ Department of Civil Engineering, \\ Aristotle University of Thessaloniki, Greece \\ ${ }^{4}$ Department of Mechanical Engineering, \\ T.E.I. of Central Macedonia, Greece
}

\begin{abstract}
It is well known that inventory collection is one of the most demanding tasks for developing a risk scenario, unless extensive information is already available. Existing data from the City Planning Office archives of the Municipality have been utilized in combination with targeted in-situ inspections of selected building blocks, in order to provide an adequate recording of a representative sample of the building stock in the city of Serres (northern Greece) that will later be used for the vulnerability assessment and the loss estimation for selected seismic scenarios within the framework of the research program SeiVAS. More than 2000 buildings have been inspected, accounting for about $20 \%$ of the building stock in the city. Recorded data include general information of the buildings (i.e. age, height, use) as well as structural aspects. All data gathered were processed in an in-house developed software application and visualized in space using the ArcGIS platform. An initial grading is given to each building adopting the (Greek) Earthquake Planning and Protecting Organization procedure and the background to be used in the final stages of the research program, utilizing appropriate fragility curves for
\end{abstract}


the corresponding building classes subjected to various seismic scenarios, has been developed.

Keywords: building stock, inventory, vulnerability, seismic risk, loss estimation.

\section{Introduction}

During the last decades, a growing interest has been observed for seismic risk studies in a number of European cities, particularly those located in the southern part, where earthquake activity and its consequences are significantly higher. The main reason is related to the widely accepted fact that seismic risk scenarios and estimation of the economic and human losses incurred by an earthquake are useful tools for seismic risk management and for prioritizing the pre-earthquake strengthening of the built environment. A decent number of earthquake damage (and loss) scenario studies appeared wherein some of the most advanced techniques have been applied to the urban habitat of European cities [1-8].

Several large scale research projects have been carried out in Europe and worldwide focusing on seismic vulnerability and risk analysis of buildings, lifelines and infrastructures. RiskUE (2001-2004) [9] and LESSLOSS (20042007) [10] evaluated the seismic hazard and structural vulnerability of several European cities in order to estimate the associated seismic risk. NERA (20102014) [11] was an EC infrastructure project that integrated key research infrastructures in Europe for monitoring earthquakes and assessing their hazard and risk. Syner-G (2009-2013) [12] focused on the systemic seismic vulnerability and risk analysis of buildings, lifelines and infrastructures providing an open source software tool to evaluate seismic vulnerability and losses considering both physical and socio-economic aspects. The WHE-PAGER project (2007-2011) [13] was an effort to summarize worldwide construction types, building inventory and seismic vulnerability, aiming mainly at the development of a rapid postearthquake casualty estimation program as well as to examine hypothetical scenarios for planning purposes. The Global Earthquake Model (GEM) [14] is a public/private partnership initiated and approved by the Global Science Forum of the OECD-GSF that aims to be the uniform, independent and open access standard to calculate and communicate earthquake hazard and risk worldwide.

In Greece, a number of vulnerability studies that resulted in seismic risk scenarios and loss estimation of the building stock have been carried out for various cities by the Aristotle University of Thessaloniki research team, members of which are included in the authors of the present work. The AUTh team adopts the hybrid approach initially proposed by Kappos et al. [15], combining the results of inelastic dynamic analyses of typical building classes for selected input motions with available (usually limited) statistical damage data from previous earthquakes. The first applications of this method have been utilizing damage probability matrices (DPM) and was applied to the building stock of Thessaloniki [15] and Volos [16]. Later versions have enhanced the hybrid procedure introducing the use of fragility curves [17, 18], instead of DPMs, that have been derived for practically all building typologies that are present in the building stock of Greek cities. The first application of the enhanced procedure has been applied once again in 
Thessaloniki, within the framework of the Risk-UE project [19] where the building stock has been updated to include newer, with regards to the original database, buildings. Probably the most comprehensive application of the AUTh hybrid procedure has been applied to the cities of Grevena (Greece) and Düzce (Turkey) within the framework of the SRM-DGC project [20] and included the latest version of the fragility curves that will also be utilized in this study. An attempt to use the AUTh hybrid approach and develop loss estimation scenarios in cases where the building stock data are not as detailed as desired has been carried out by Karakostas et al. [21] within the MASSIVE project for the cities of Athens (Greece) and L'Aquila (Italy). The same building typologies have also been used by Kappos et al. [22] for direct loss estimation (without the use of DPMs or fragility curves) and comparison with available damage data for the building stock of Ano Liosia (Athens) that was heavily struck by the 1999 Athens earthquake, using several series of seismic hazard scenarios.

Seismic risk scenario projects for the Greek building stock have also been developed by several other researchers. Anagnostopoulos et al. [23] have presented the SEISMOCARE GIS tool, aiming to provide a user friendly, menudriven portable system with built-in as well as user defined functions and assumptions. Eleftheriadou et al. [24] have carried out a large scale project in order to compare the DPM based damage estimates with available data from repair/strengthening or replacement cost in the extended urban region of Athens, struck by the 1999 earthquake.

\section{The SeiVAS project}

The study presented herein has been carried out within the framework of the research program SeiVAS: Seismic Vulnerability Assessment of the building stock in the city of Serres (http://seivas.net/), coordinated by the Department of Civil Engineering and Surveying Engineering and Geoinformatics of the T.E.I. of Central Macedonia, Greece, in cooperation with scientists from the Institute of Engineering Seismology and Earthquake Engineering (ITSAK-EPPO) and the Civil Engineering Department of the Aristotle University of Thessaloniki.

The first phase of the project (WP1-WP3) involves the estimation of seismic hazard in the greater area of Serres and the development of a series of seismic scenarios that correspond to various levels of seismic action (fig. 1). Furthermore, utilizing state-of-the-art techniques, the soil profile is identified in several locations of the city, allowing the estimation of the strong ground motion and the development of the corresponding response spectra. The next phase of the project (WP4-WP5) involves the inventory of a reliable sample from the building stock in Serres and the development of a database with all building characteristics that affect their seismic response. Moreover, seismic vulnerability functions are developed, utilizing Greek as well as international experience, tailored to the special characteristics of the buildings stock. Finally, combining the outcome of the aforementioned actions, some series of seismic risk scenarios are developed (WP6), including the estimated losses in monetary terms as well as predictions for the post-earthquake tagging of the buildings. After a brief presentation of the first 
phase of the project, the paper focuses on the inventory of the building stock and includes some pilot seismic loss scenarios in the next sections.

In order to evaluate properly the seismic risk of the building stock in an urban region, it is imperative to follow a procedure that includes several stages, concerning the area seismicity and the soil deposit characteristics and dynamic response. The first step towards the identification of the most detrimental earthquake scenarios in the investigated area, is to perform a region-specific seismic hazard analysis at bedrock level. The assessment of seismic hazard takes into consideration seismic sources in the broader area and employs suitable ground motion prediction equations. Available seismological information of the area, such as data of historical earthquakes, identified seismic faults, macroseismic observations etc., are properly validated and utilized during the study. After processing all aforementioned data, it is possible to propose seismic scenarios at bedrock level for various selected earthquake return periods.

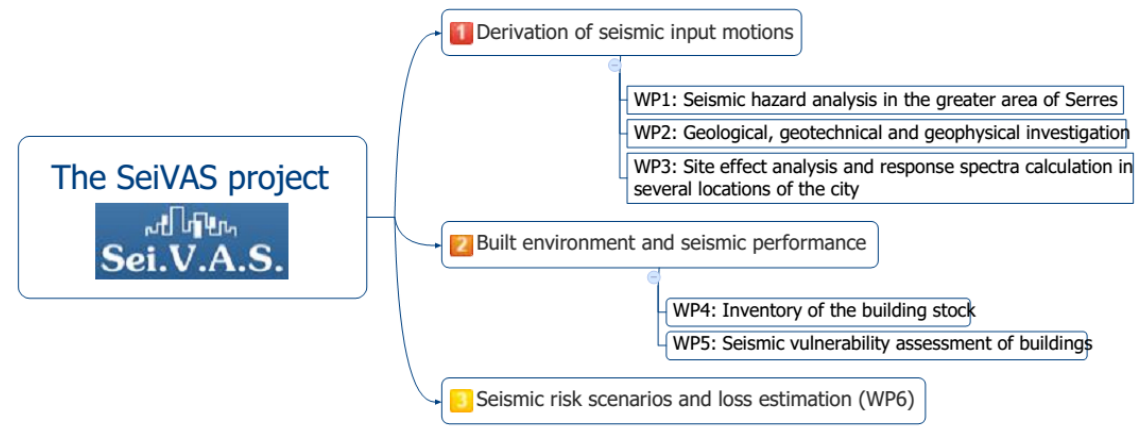

Figure 1: The SeiVAS project framework.

In the next stage of the procedure, a series of geological, geotechnical and geophysical data is utilized in order to determine the soil dynamic properties. First, data from existing geological maps of the area are evaluated, indicating three different geological formations in various city regions. Stiffer soil formations can be detected at the northern part of the city, whereas the southern part is founded on softer recent alluvia. Borehole data inside the urban area derived from existing near-surface geotechnical studies (L1-L4, fig. 2), as well as 40-45m deep boreholes at the city ring road that were provided by Egnatia Odos A.E. (L14L22), produce valuable information that assist the design of the geophysical field measurements. The geophysical survey that follows, comprises both single-station and array type measurements [25], providing results that concern the soil deposit fundamental frequency and dynamic characteristics with depth.

The final stage of the earthquake identification procedure refers to the estimation of the surface seismic motion, based on the seismic hazard results at bedrock level (soil type A, according to EC8) and the particular soil deposit characteristics of selected sites in the area of interest. One-dimensional soil dynamic response analyses, taking into consideration alternate earthquake levels 
according to predefined seismic hazard scenarios, result in acceleration timehistories at surface level. Soil non-linearity is accounted for during the numerical investigation, employing equivalent linear soil response based on selected Ggamma-D curves that consider the reduction of soil shear modulus and the increase of material damping with increasing soil shear deformation [26, 27]. The acceleration response spectra calculated at the surface can be further used during the seismic risk investigation of the building stock in the city of Serres.

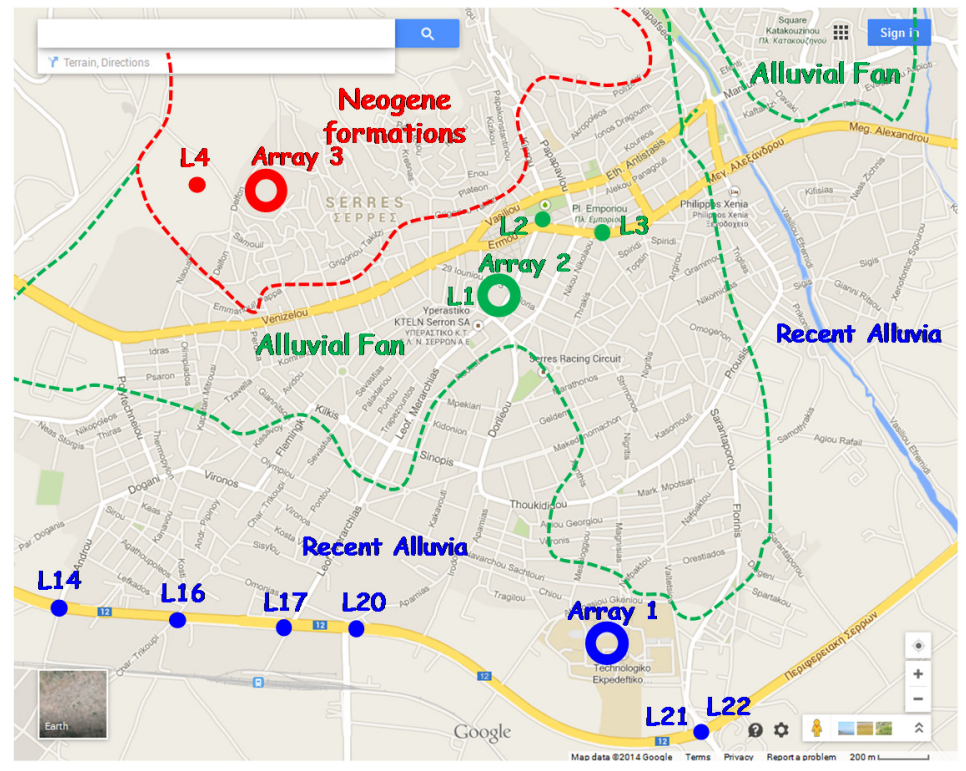

Figure 2: Locations of existing geotechnical data (L1-L4, L14, L16, L17, L20, L21, L22) and sites of ambient noise arrays (Array 1: TEI, 2: Prefecture, 3: Tanks). Three main surface geologic units (Recent Alluvia, Alluvium Fans, Neogene Formations) covering the urban area of Serres are shown (updated image after Theodoulidis et al. [25], map source: Google ${ }^{\mathrm{TM}}$ maps web service).

\section{Inventory of the building stock}

The first, and usually most time-demanding, task required for the development of seismic loss scenarios is related to the collection of reliable data for the building stock; this is a necessary step that is required for the vulnerability and loss assessment in any given area. Existing data from the City Planning Office archives of the Serres Municipality have been utilized but they were rather limited, focusing mainly on newly constructed buildings and changes that took place over the last few years. Moreover, not all buildings in each area (e.g. building block) were covered, whereas information critical for the vulnerability assessment was missing (e.g. structural system). This information has been utilized in combination with 
targeted in-situ inspections of selected building blocks, in order to provide an adequate recording of a representative sample of the building stock in the city (fig. 3). More than 2000 buildings have been inspected accounting for over $20 \%$ of the building stock in the city (2046 buildings located in 164 blocks are included in the present paper while information for about 400 more buildings is currently under process and will be used in the final scenarios of the SeiVAS project).
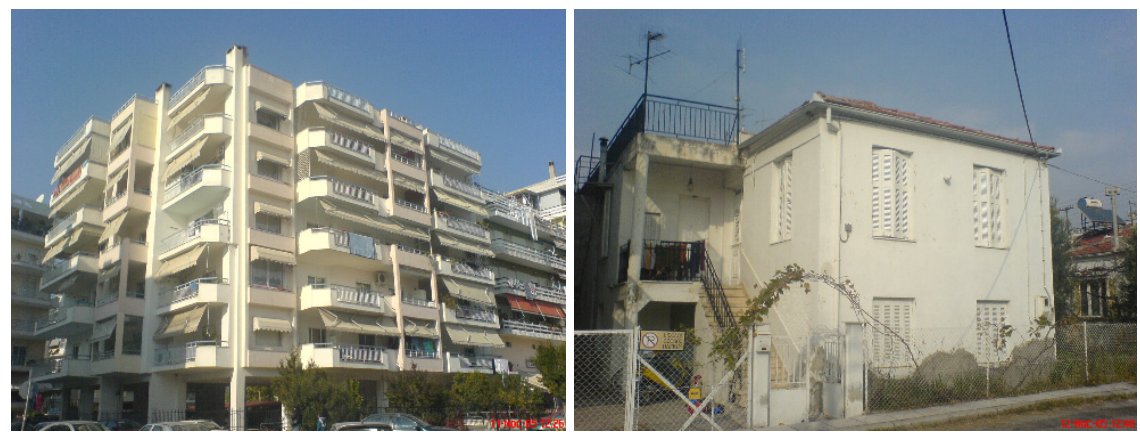

Figure 3: Typical reinforced concrete (left) and masonry (right) buildings.

Recorded data include general information of the buildings as well as structural aspects based on the experience of the previous AUTh team projects [17, 18, 20] and the corresponding available vulnerability functions (i.e. fragility curves). A data collection form has been prepared that included:

1. Identification of the building (ID, building block, street name/number);

2. General information that affects the seismic performance (number of storeys, built area, age that can be directly associated with the contemporary seismic code etc.);

3. Structural information such as material (reinforced concrete, masonry, steel etc.), structural system (e.g. moment frame or dual system for $\mathrm{R} / \mathrm{C}$ buildings), infill walls pattern (bare/regularly infilled/soft storey);

4. Special structural information such as the presence of short columns in $\mathrm{R} / \mathrm{C}$ buildings, the number of basements if present and the existence of adjacent buildings.

All data gathered were processed in an in-house developed software application (fig. 4) and visualized in space using the ArcGIS platform. The results of the inventory process provides extensive and valuable information regarding the built environment in the city of Serres. For example, figure 5 presents the evolution of the building stock in the $20^{\text {th }}$ century since nowadays and it is clear that a significant number of old buildings (earlier than the 50s when the first Greek Codes were introduced) is still present. Nevertheless, the comparison with the respective built area reveals that these buildings are usually small, low-rise masonry structures and their significance in monetary terms is greatly reduced. Figure 6 presents the spatial distribution of the building stock with regard to the structural material (URM or R/C) and the seismic code for R/C buildings. 


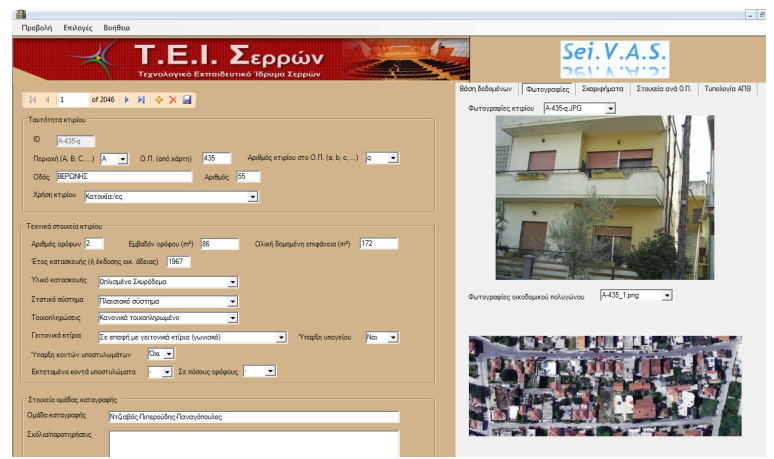

Figure 4: In-house developed software for building data processing.

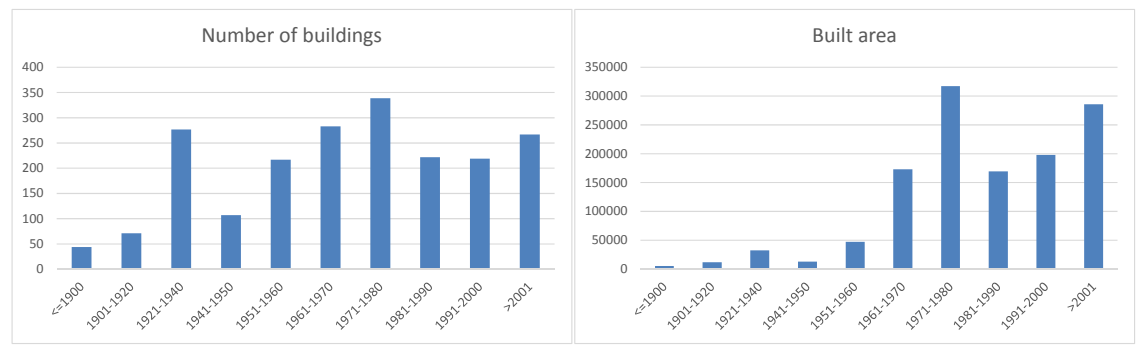

Figure 5: Evolution of building construction in Serres in terms of number of buildings (left) and built area (right).
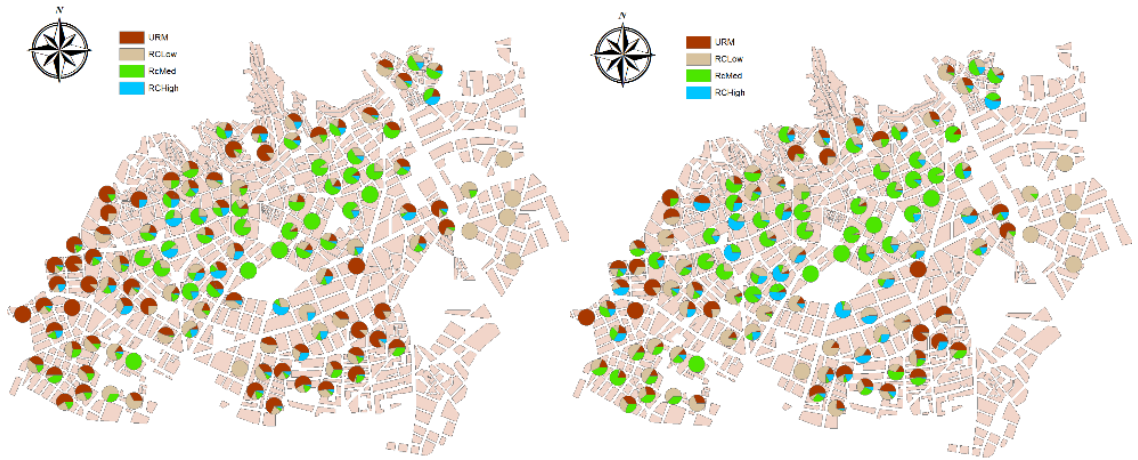

Figure 6: Spatial distribution of the building stock in Serres in terms of number of buildings (left) and built area (right). (URM: unreinforced masonry, RCLow: R/C buildings - 1959 Greek code or older, RCMed: R/C buildings - 1985 Greek code, RCHigh: modern R/C buildings). 


\section{The EPPO grading procedure}

A simplified approach to evaluate the vulnerability of existing buildings is to assign specific score points for each main structural characteristic, based on information derived from a quick inspection. This method results in a single score for the structure which is indicative of the building's resistance capacity during an earthquake event. In the present research, the methodology proposed by EPPO (Earthquake Planning and Protection Organization) [28], based on the guidelines provided by FEMA 154 [29], has been applied.

According to the EPPO methodology, the properties that mainly affect the score of the building concern the seismic zone of the area, the structural type and the employed Seismic Code. The procedure examines several structural types common in Greece urban areas, such as reinforced concrete bearing systems, either with moment resistant frames or with concrete bearing walls, masonry buildings and steel buildings. With respect to the Seismic Code, the construction period before 1959 lacks any earthquake-related regulations during the design. In 1959 the first guidelines regarding the consideration of seismic loading were introduced, that were later (1985) complemented with some additional clauses. The first coherent Seismic Code was enforced in 1995 and was completed in 2000 reaching each final stage. Structural properties that contribute to the earthquake resistance, such as design according to a modern Seismic Code or reliable bearing system, receive a positive grade, whereas any source of structural vulnerability receives a negative grade. This procedure may present several flaws, with more characteristic the case where a negative total score is calculated for structures of poor structural properties and old age in areas of increased seismicity. Nevertheless, it is a simple and straightforward first approach to evaluate the vulnerability of the building stock of an entire city.

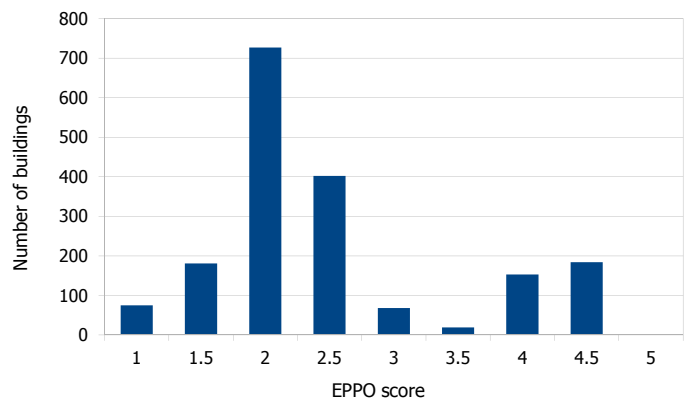

Figure 7: Building scores using the EPPO procedure.

\section{Discretization into appropriate geographical units}

Discretization provides an extensive set of functions and operations through which the desired results for each cell are produced. A discretized cell, having geographical designation, can act as an independent unit. The main feature of this 
process is the homogeneity of the parameters shown in each cell separately, and which can be processed either independently or associated with the corresponding parameters of other cells. The registered information, derived from recordings at the building level is promoted to the cell level. It should be noted that the important key issue for the use of this method is the concept of precision that is associated with the dimension (cell size), especially when it comes to data derived from stratified random sampling. The geographical units have to be small enough to be able to capture the spatial distribution of the examined information but adequately large in order not to lose much information regarding data with small probability of occurrence [20] (i.e. building classes with a small number of buildings).

The stratified random sampling method was chosen for the records of the building blocks. Stratification is the process of dividing the members of the population into homogeneous subgroups before sampling takes into account the study characteristics (in this case the synthesis of the building stock). Due to the fact that the number of registrations (blocks) shows a different result according to the optimal dimension of cells (cell size), analyses were performed for cell size $250 \mathrm{~m} \times 250 \mathrm{~m}$ and $500 \mathrm{~m} \times 500 \mathrm{~m}$, considering the average results from the original recordings of blocks characteristics. In this way, the optimal cell size for the needs of this study seems to be the $500 \mathrm{~m}$ x $500 \mathrm{~m}$ [30].

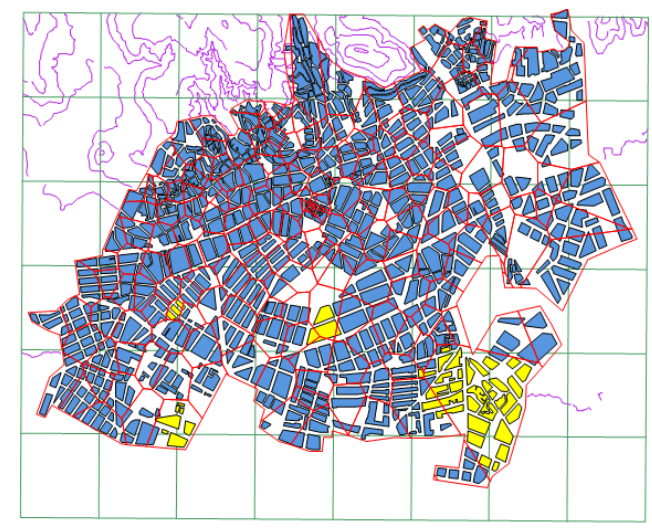

Figure 8: Alternative approaches for geographical unit discretization.

The form of the urban area in the city of Serres, as that depicted in map level, displays a number of factors directly related to the features of an irregular geometry, which has to do with the development of the city throughout the years. Specifically displays:

1. Irregular complex forms which were developed at later built residential space.

2. Heterogeneity in the form and layout of the built space which coexist with open field spaces and developed residential units before 1923. This means that the form of the urban area is extremely far from homogenous modules 
[31], assumption that is made when an analysis based on the concept of the discretization is applied.

On this basis and given the fact that the adjacent blocks than the selected ones, will have similar behavior of the studied characteristic (based on stratified sampling), we consider the center of gravity of the block for which we have a record and calculate the influence on the adjacent ones where there are no records using a geostatistical analysis method with the k-nearest neighbor, where $\mathrm{k}=1$ ). Thereby, different sized modules are created where all the information is concentrated in the center of gravity of the recorded block and thus each derived module has this information registered. Then the information that is present in each module (and derived from the record of a single building block) is recorded to the adjacent blocks in which there are no records.

The main feature of the modules is the fact that they consist of a pattern, which is repeated in different scales. In this light irregular, complex forms are created, arising from the application of a clear rule that organizes them (k-nearest neighbor with $\mathrm{k}=1$ ), and thus characterized by a self-similarity which can be used to derive safe conclusions by using the stratified random sampling method.

All versions of geographical unit discretization will be utilized in the final loss estimation scenarios of the SeiVAS project. The basic scenarios will adopt the $500 \mathrm{~m}$ grid cell approach since it includes only actually recorded information. This choice provides enhanced information compared to the approach when the building block is used as the geographical unit where data corresponding to rare building classes can easily be lost in favor of the ones that appear more in the building stock.

\section{Acknowledgements}

This research has been co-financed by the European Union (European Social Fund-ESF) and Greek national funds through the Operational Program "Education and Lifelong Learning" of the National Strategic Reference Framework, research project "Sei.V.A.S.: Seismic Vulnerability Assessment of the building stock in the city of Serres", in ARCHIMED III Research Funding Program: "Strengthening Research Groups at the TEI of Serres" (mis 380873).

The contribution of the under graduate students (Department of Civil Engineering and Surveying Engineering and Geoinformatics of T.E.I. of Central Macedonia), who assisted in the in-situ inspections of the building blocks, is also acknowledged.

\section{References}

[1] Barbat, A.H., Moya, F.Y. \& Canas, J.A., Damage Scenarios Simulation for Seismic Risk Assessment in Urban Zones. Earthquake Spectra, 12(3), pp. 371-394, 1996.

[2] Barbat, A.H., Carreño, M.L., Pujades, L.G., Lantada, N., Cardona, O.D. \& Marulanda, M.C., Seismic vulnerability and risk evaluation methods for urban areas. A review with application to a pilot area. Structure and 
Infrastructure Engineering: Maintenance, Management, Life-Cycle Design and Performance, 6(1-2), pp. 17-38, 2010.

[3] Bard, P.Y., Bour, M., Duval, A.M., Godefroy, P., Martin, Ch., Meneroud, J.P., Mouroux, P., Terrier, M., Thibault, Ch., Velkov, P. \& Vidal S., Seismic zonation methodology for the city of Nice. Progress report. Proc. of the $5^{\text {th }}$ International Conf. on Seismic Zonation, Nice, France, pp. 1749-1784, 1995.

[4] D’Ayala, D.F., Spence, R.J.S., Oliveira, C.S., \& Silva, P., Vulnerability of buildings in historic town centres: A limit-state approach. 11th World Conference on Earthquake Engineering (Acapulco, Mexico), Paper No. 864 [CD ROM Proceedings], Pergamon, 1996.

[5] Dolce, M., Kappos, A., Masi, A., Penelis, Gr. \& Vona, M., Vulnerability assessment and earthquake damage scenarios of the building stock of Potenza (Southern Italy) using Italian and Greek methodologies. Engineering Structures, 28 (3), pp. 357-371, 2006.

[6] Erdik, M., Aydinoglu, N., Fahjan, Y., Sesetyan, K., Demircioglu, M., Siyahi, B., Durukal, E., Ozbey, C., Biro, Y., Akman, H. \& Yuzugullu, O., Earthquake risk assessment for Istanbul metropolitan area. Earthquake Engineering and Engineering Vibration, 2(1), pp. 1-23, 2003.

[7] Faccioli E., Pessina V., Calvi, G.M., \& Borzi, B., A study on damage scenarios for residential buildings in Catania city. Journal of Seismology, 3(3), pp. 327-343, 1999.

[8] Strasser, F.O., Bommer, J. J., Şeşetyan, K., Erdik, M., Çağnan, Z., Irizarry, J., Goula, X., Lucantoni, A., Sabetta, F., Bal, I.E., Crowley, H. \& Lindholm, C., A Comparative Study of European Earthquake Loss Estimation Tools for a Scenario in Istanbul. Journal of Earthquake Engineering, 12(2), 2008.

[9] Mouroux, P., \& Brun, B.Le., Presentation of RISK-UE Project. Bulletin of Earthquake Engineering, 4(4), pp. 323-339, 2006.

[10] Spence R., LESSLOSS Risk Mitigation for Earthquakes and Landslides. Report - 2007/07 Earthquake Disaster Scenario Prediction and Loss Modelling for Urban Areas, IUSS Press, 2007.

[11] NERA: Network of European Research Infrastructures for Earthquake Risk Assessment and Mitigation, http://www.nera-eu.org/

[12] Pitilakis, K., Franchin, P., Khazai, B. \& Wenzel, H., (eds). SYNER-G: Systemic Seismic Vulnerability and Risk Assessment of Complex Urban, Utility, Lifeline Systems and Critical Facilities, ISBN 978-94-017-8835-9, Springer Science+Business Media, Dordrecht, 2014.

[13] Porter, K.A., Jaiswal, K.S., Wald, D.J., Greene, M. \& Comartin, C., WHEPAGER Project: A new initiative in estimating global building inventory and its seismic vulnerability. Proc. of the 14th World Conf. on Earthquake Engineering. Beijing, 2008.

[14] GEM - Global Earthquake Model, www.globalquakemodel.org

[15] Kappos, A.J., Stylianidis, K.C. \& Pitilakis, K.D., Development of seismic risk scenarios based on a hybrid method of vulnerability assessment. Natural Hazards, 17(2), pp. 177-192, 1998. 
[16] Kappos, A.J., Pitilakis, K.D., Morfidis, K. \& Hatzinikolaou, N., Vulnerability and risk study of Volos (Greece) metropolitan area. Proc. of the 12th European Conf. on Earthquake Engineering, London, 2002.

[17] Kappos, A.J., Panagopoulos, G., Panagiotopoulos, C. \& Penelis, G., A hybrid method for the vulnerability assessment of R/C and URM buildings. Bulletin of Earthquake Engineering, 4(4), pp. 391-413, 2006.

[18] Kappos, A.J. \& Panagopoulos, G., Fragility curves for reinforced concrete buildings in Greece. Structure and Infrastructure Engineering, 6(1-2), pp. 39-53, 2010.

[19] Kappos, A. J., Panagopoulos, G. \& Penelis, G., Development of a seismic damage and loss scenario for contemporary and historical buildings in Thessaloniki, Greece. Soil Dynamics and Earthquake Engineering, 28(1011), pp. 836-850, 2008.

[20] Kappos, A. J., Panagopoulos, G. K., Sextos, A. G., Papanikolaou, V. K. \& Stylianidis, K. C., Development of comprehensive earthquake loss scenarios for a Greek and a Turkish city - structural aspects. Earthquakes and Structures, 1(2), pp. 197-214, 2010.

[21] Karakostas, Ch, Lekidis, V., Kappos, A.J., Panagopoulos, G.K., Keramitsoglou, I. \& Kontoes, Ch., Evaluation of seismic vulnerability of buildings in Athens and L'Aquila in the framework of the MASSIVE seismic mitigation system. Proc. of the $15^{\text {th }}$ World Conf. on Earthquake Engineering, Lisbon, 2012.

[22] Kappos, A.J., Lekidis, V., Panagopoulos, G., Sous, I., Theodulidis, N., Karakostas, C., Anastasiadis, T., Salonikios, T. \& Margaris, B.N., Analytical Estimation of Economic Loss for Buildings in the Area Struck by the 1999 Athens Earthquake and Comparison with Statistical Repair Costs. Earthquake Spectra, 23(2), pp. 333-355, 2007.

[23] Anagnostopoulos, S. A., Providakis, C., Salvaneschi, P., Athanasopoulos, G., \& Bonacina, G., SEISMOCARE: An efficient GIS tool for scenariotype investigations of seismic risk of existing cities. Soil Dynamics and Earthquake Engineering, 28(2), pp. 73-84, 2008.

[24] Eleftheriadou, A. K., Baltzopoulou, A. D., \& Karabinis, A. I., Seismic Risk Assessment of Buildings in the Extended Urban Region of Athens and Comparison with the Repair Cost. Open Journal of Earthquake Research, 3, pp. 115-134, 2014.

[25] Theodoulidis, N., Margaris, B., Savvaidis, A., Kirtas, E. \& Rovithis, E., Defining Shallow Structure Properties by Composing Ambient Noise and Geological Data for Seismic Risk Mitigation: The Case of Serres City (Northern Greece). Proc. of the 1st International GEOMAPPLICA Conf., pp. 52-58, Skiathos, Greece, 2014.

[26] Seed, H.B. \& Idriss, I.M., Soil Moduli and Damping Factors for Dynamic Response Analysis. Report no. EERC 70-10, Earthquake Engineering Research Center, University of California, Berkeley, 1970.

[27] Vucetic, M. \& Dobry, R., Effect of soil plasticity on cyclic response. Journal of Geotechnical Engineering, ASCE, 117(1), pp. 89-107, 1991. 
[28] EPPO (Earthquake Planning and Protection Organization), Technical Instructions of Pre-seismic Assessment of Public Buildings (in Greek), Athens, 2000.

[29] FEMA 154, Rapid Visual Screening of Buildings for Potential Seismic Hazards: A Handbook, $2^{\text {nd }}$ ed., Applied Technology Council, Redwood City, CA, 2002.

[30] Longley, P., Batty, M. \& Shepherd, J., The size, shape \& dimension of Urban Settlements. Transactions of the Institute of British Geographers, 16, pp. 75-94, 1991.

[31] Frankhauser, P., The Fractal Approach, a new tool for the spatial analysis of urban agglomerations, Population, 10(1), pp. 205-240, 1998. 